\title{
Dilbilim ve Edebiyat: Edebi Eleştirmen İçin Bir Araç Olarak Üslup Çözümlemesi
}

\author{
Dan McIntyre, Huddersfield Üniversitesi, İngiltere* \\ Çev. Tuba YILMAZ**
}

\section{Giriș}

İngiliz Edebiyatının üniversitede kendi başına bir ders olarak ortaya çıktığı 1960'lardan beri, edebiyat çalışmaları ve dil çalışmaları arasındaki ilişki acı çekişmeler hâlindedir. Edebî eleştirmenler edebî metinlerin çözümlemesinde dilbilimle iştigal edenler tarafından kullanılan 'soğuk', 'bilimsel' yaklaşıma karşı çıkar, dilbilimcilerse edebiyat üzerine çalışan meslektaşlarını ürettikleri tahlillerde çok belirsiz ve öznel olmakla itham ederler. Bateson ve Fowler (bk. Fowler 1971) arasındaki çatışmada açıkça görülen bu anlaşmazlık, ilgili konuları yükseltmek açısından yararlı olmakla birlikte, tartı̧̧mayı kişisel hakaret seviyesine çekmenin talihsiz etkisine uğradı. Fowler'ın Bateson'a sorduğu ünlü soru, kız kardeşinin bir dilbilimciyle evlenmesine izin verip vermeyeceğidir. Belki de bu soru iddialaşmanın/çekişmenin (argümanın) en alt noktasını temsil ediyordu. O dönemde edebiyat ile dil arasındaki ilişki çoğunlukla yersiz bir duruma gelmişti. Şüphesiz her iki disiplin içindeki akademisyenler birbirlerinden öğrenmeleri gereken çok şey olduğundan bu çekişme bir talihsizlikti. Bu makaledeki amacım, üslupbilim (stylistics) olarak bilinen dil çalışmasının alt disiplini içerisinde bulunan

\footnotetext{
* Makale metninde, orijinal metnin aksine, makalenin son kısmında (references) yer alan notları dipnot olarak çevirmeyi uygun gördük.

Metin için bk. https://pdfs.semanticscholar.org/5f77/2d0df008cca80af6f7493bda4ad78fcc0bf1.pdf

** Doktora Öğrencisi, İstanbul Medeniyet Üniversitesi, Türk Dili ve Edebiyatı, Yeni Türk Edebiyatı ABD. Türkiye. Elmek: tuba.yilmazz@hotmail.com
} 
çözümsel teknikleri kullanarak, dil ve edebiyat arasındaki bölünmeyi kapatmanın nasıl mümkün olduğunu göstermektir. Amerikan şairi E. E. Cummings'in şiirini inceleyerek dilsel biçimin edebî etkiyle nasıl ilişkili olduğunu tartıştım. Bir edebî eserin analizine dilsel bir yaklaşım kazandırmanın yorumlamayı göz ardı etmek anlamına gelmediğini göstermeyi amaçlıyorum. Daha ziyade ben, sadece üslup çözümlemesinin (stylistic analysis) belirli bir edebî metni neden bu kadar yüksek saydığını, aydınlattığını önerebilirim. Biçimcilik, bir metnin üretiminde verilen her kararın bilinçli ya da bilinçsiz olarak yapılmış olmasına rağmen, kasıtlı olduğunu varsayarak yazarın becerilerini kabul eder. Sonuç olarak üslubun amacı, dilsel biçim ile edebî etki arasındaki bağlantıyı açıklamak ve belirli bir yazının niteliğini övdüğümüzde buna karşılık verdiğimiz şeyin ne olduğunu açıklar.

\section{E. E. Cummings'in 'Dinle'[Şiiri]}

Üslup çözümlemesine nasıl başlarsınız? Tahlil edeceğiniz metinle ilgili ilk düşünceleriniz ve duygularınızla başlamak iyi bir fikirdir. Sonra gerçek çözümlemeyi yaptığınızda, ilk yorumunuzda doğru veya yanlış olup olmadığını görebilirsiniz. Bazen metnin dil yapısı, yorumunuzu desteklemeyecektir, bu durumda çözümlemeniz ışığında yorumunuzu tekrar gözden geçirmeniz gerekebilir. Bu yüzden üslupbilim (stylistics), metinleri yorumlama yöntemi olarak kullanışlıdır. O hâlde, seçtiğimiz şiire göz atarak başlayalım.

Listen (Dinle), E. E. Cummings' in 1964 yılında yayımladığg 73 Şiirler koleksiyonundaki 63. numaralı eseridir. Koleksiyonda yer alan şiirlerin hiçbiri başlıklara sahip değil, bunun yerine sayı ile anılıyorlar. ${ }^{1}$ Bununla birlikte, referans kolaylığı için şiirin ilk satırını bir başlık olarak kullandım. Şiir aşağıda verilmiştir. Dinle şiiri, Cummings tarzının tipik bir örneğidir ve 'geleneksel' şiir ile karşılaştırıldığında çarpıcı bazı şekil düzensizlikleri içerir. Mesela, normalde beklediğiniz büyük harf kullanımının eksikliğini, noktalama işaretlerinin garip biçimde kullanılmasını ve belirli ifadelerin görünüşte garip yapisinı fark edebilirsiniz.

1 Her ne kadar çoğu insan, E[dward] E[stlin] Cummings'in isminin küçük harfle yazıldığını düşünse de E. E. Cummings Derneği (Society), son zamanlarda, genellikle yanlış olduğuna inanılan bu fikri düzeltmek için çalışıyor. Bu konuyla ilgili daha fazla bilgiyi aşağıdaki adreste bulabilirsiniz:

http://www.gvsu.edu/english/cummings/caps.htm. Cummings'in kitaplarının pek çoğunda, adının baş harflerinin kapağın üzerine küçük harfle yazıldığını ve muhtemelen kabul edilebilir olduğunu unutmayın. Karışıklığı önlemek için, bu makalede, Cummings'in isminin geleneksel, büyük harfli yazımını kullanıyorum. 


\section{[1] (listen) this a dog barks and how crazily houses eyes people smiles}

[5] faces streets steeples are eagerly tumbl ing through wonder ful sunlight

[10] -lookselves,stir:writhe o-p-e-n-i-n-g are (leaves; flowers) dreams ,come quickly come

[15] run run with me now jump shout (laugh dance cry sing) for

it's Spring

[20] - irrevocably;
and in
earth sky trees
:every
where a miracle arrives

[25] (yes)

$$
\begin{aligned}
& \text { you and I may not } \\
& \text { hurry it with } \\
& \text { a thousand poems } \\
& \text { my darling }
\end{aligned}
$$

[30] but nobody will stop it (dinle)

bu bir köpek havlar ve nasıl da çılgınca evler gözler insanlar gülüşler yüzler caddeler kuleler istekle y1k1lı yor mükem mel günışığında - bak-

$$
\begin{aligned}
& \text { kendi,karıştır:kıvran } \\
& \text { a-ç-1-y-o-r }
\end{aligned}
$$

lar(yapraklar; çiçekler) rüyalar ,gel çabucak gel koş koş benimle şimdi zıpla bağır (gül dans et ağla şarkı söyle) çünkü

Bahar

- dönüşü olmaksızın ve içine yeryüzü gökyüzü ağaçlar :her yere bir mucize ulaşır

(evet)

sen ve ben acele etmeyebiliriz bin şiirle sevgilim çünkü hiç kimse durduramaz

With All The Policemen In The World

Dünyadaki Bütün Polisler (E. E. Cummings, 73 Poems) 
Cummings'in şiirlerinin hepsinde çok miktarda sapma (deviasyon) kullanılmıştır ve Dinle de buna dahildir. Şiir aşağıdadır:

Cummings' in, şiirlerinde sapma (deviasyon) kullanmasının nedenlerinden biri, basmakalıp şiir gelenekleriyle başa çıkma arzusudur. Bununla birlikte, sapmayı kullanması yalnızca şok değeri için olmadığı gibi, yaptığı dilsel seçimlerin de hiçbiri keyfî değildir. Buna rağmen, bu kadar sapma, şiirlerini yorumlamamızı zorlaştırabilir. Eskiden, bazı eleştirmenler görünüşte tuhaf kullanımı olan Cummings' in dilini göz ardı ettiler; bunun, anlamı yorumlayıcı bir öneme sahip olmadı ğını iddia ettiler. Örneğin, 1954'te eleştirmen R. P. Blackmur, Cummings'in şiirlerindeki garip dil seçenekleri hakkında şunları söylemişti:

“(...) bu özelliklerin bugünkü kapsamlı bir değerlendirilmesi çok az önem taşımaktadır ve şiirlerin anlamına neredeyse hiç değinilmemektedir" (Blackmur 1954: 320).

Blackmur'un öne sürdüğü görüş günümüz için oldukça eski. Onun 'özellikler’ olarak değindiği şey, aslında çok önemli dil sapmalarıdır ve herhangi bir yazının her unsurunun yorumlayıcı bir öneme sahip olduğunu varsaymamız önemlidir. Bunun gerçekte olup olmadığını sorabilirsiniz. Bir metnin her bir parçasından gerçekten anlam çıkarıyor muyuz? Elimizdeki kanıtlar yaptığımızı önermişti. Van Peer $(1980$; 1986) gibi araştırmacılar, okuyucuların gerçekten de bir metnin en küçük ayrıntılarını alıp anlamlı bir yorum oluşturmak için kullandıklarını keşfettiler. Şiirimizin üslupsal çözümlemesi, onun içindeki ön planlamayı ayrıntılı olarak açıklamamıza imkân sağlayacak ve üslupbilimin edebî eleştirmen için ne kadar değerli bir araç olabileceğini gösterecektir.

Şiirin ilk yorumu ile başlayalım. Cummings'in şiirlerinin çoğunda olduğu gibi Dinle şiiri de yaklaşan baharın gelişine bağlı olarak ortaya çıkan sevinç ve yeniliğin bir kutlaması gibi görünüyor. Şiirde dinamik bir his var ve elbette yeni hayata göndermelerle birlikte küçük cinsel çağrışımları da görebiliyoruz. Şiir, aynı zamanda şairin mutluluğunu paylaşmak ve doğal dünyanın kaçınılmaz olduğunu ve bunun kapsadığı her şeyi kabul etmek için sevgiliye bir hitap gibi görünüyor. Cummings'e özgü tuhaf mizahı yaratmak -bu durumda- doğanın kendi rotasında seyretmesine izin vermek için sevgilisine yönelik -çift - anlamlı bir savunmadır. Şiir, baharın ele alınış biçiminde açık bir şekilde tanımlayıcı değildir. 
Bunun yerine, bir dizi rastgele görüntü (ör. Evler, gülümsemeler, insanlar, sokaklar) ve eylemler ile sunulmuş gibi görünüyor. Bahar ile ilgili bir şiir olarak algıladığımız şeyi yaratma faktörünün önemine 3. bölümün 1. kısmında bakacağız. Özetle, konuşmacı, baharın gelişi gibi sevgisinin kaçınılmaz olduğunu ve durdurulamayacağını söylüyor.

'Dinle', konunun karmaşıklığı açısından özellikle zor bir şiir değildir. Daha zor olan, Cummings' in genel yorumlama için kullanmayı seçtiği pek çok “garip” üslup özelliği ni şiirle ilişkilendirmektir. Bunu, şiirin en öne çıkan özelliklerine bakarak başarabiliriz; yani şiirdeki küçük parçalar sıra dışı göründükleri için öne çıkıyorlar. Şimdi, şiirin ilk yorumunu yaptığımıza göre, devam edip onun kapsamlı bir dilsel çözümlemesine geçebiliriz.

\section{3. Çözümleme}

'Dinle'nin ilk yorumu, sadece şiirdeki kelimelere bakmanın bir sonucu olarak ortaya çıktı. Örneğin, özellikle sapkın (deviant) gramer ve yazıbilimsel (graphological) unsurlar hakkında düşünmüyorum.Daha sonra, sözcüksel özelliklerin incelenmesi daha teferruatlı bir dilbilimsel çözümleme ile başlamak için iyi bir yerdir. Diğer şiirsel etkilerin, daha sonra şiirin genel anlamına nasıl katkıda bulunduğunu ele alacağız.

\subsection{Sözlüksel Özellikler}

İlk önce şiirdeki açık sınıf kelimeleri düşünelim. Belirteç (determiner) (Meselâ; this, that, the) ve edat (Meselâ; in, at, on) gibi kapalı sınıf kelimelerin (gramerce) aksine, açık sınıf kelimeler dildeki anlamın büyüklüğünü taşırlar. Kapalı sınıf kelimeler cümlede "yapıştırıcı" (glue) gibi davranır ve açık sınıf sözcükleri anlamlı düzenlemelerle (cümleler) birleştirir. Tablo 1, açık sınıf kelimelerin şiir boyunca nasıl dağıtıldığını ve isim, fiil, sıfat veya zarf olup olmadığııı gösterir. 


\begin{tabular}{|l|l|l|l|}
\hline İSİM & TEMEL EYLEM & SIFATLAR & ZARFLAR \\
\hline Köpek & Dinle & mükemmel & çllgınca \\
\hline evler & Havla & & istekle \\
\hline Gözler & Yıkılıyor & & çabucak \\
\hline İnsanlar & Bak & & dönüşü olmaksızın \\
\hline Gülüşler & Karıştır & & \\
\hline yüzler & kıvran & & \\
\hline caddeler & Açıyor & & \\
\hline kuleler & gel (X2) & & \\
\hline günış1 ̆̆1 & koş (X2) & \\
\hline yapraklar & Zıpla & & \\
\hline çiçekler & Bağır & & \\
\hline rüyalar & Gül & & \\
\hline yeryüzü & dans et & & \\
\hline gökyüzü & Ağla & & \\
\hline ağaçlar & Şark1 söyle & & \\
\hline mucize & '[i]s = is & & \\
\hline şiirler & Ulaş & & \\
\hline polisler & acele etmek & & \\
\hline dünya & Durdurmak & & \\
\hline $\mathbf{1 9}$ & $\mathbf{2 1}$ & \\
\hline
\end{tabular}

Tablo 1 Açık sınıf kelimelerinin 'Dinle'deki dağılımı

Yukarıdaki tablodan şiirin esas olarak isimler ve fiillerden oluştuğunu görebiliriz.

İsimler çoğunlukla somuttur - yani fiziksel nesnelere atıfta bulunurlar - ve isimlerden sadece ikisi soyuttur (rüyalar ve mucize). İsimleri, iki kaba anlam alanı veya semantik alanlara bölmek mümkündür. Tablo 2 bunu nasıl yapabileceğimizi göstermektedir:

\begin{tabular}{|l|l|}
\hline \multicolumn{1}{|c|}{ DOĞA İLE İLGiLI İSIMLER } & \multicolumn{1}{|c|}{ INSANLA İLGILİ İSİMLER } \\
\hline $\begin{array}{l}\text { Köpek, günışığı, yapraklar, çiçekler, yeryüzü, gökyüzü, } \\
\text { ağaçlar, mucize, dünya }\end{array}$ & $\begin{array}{l}\text { Evler, gözler, insanlar, gülüşler, } \\
\text { yüzler, caddeler, rüyalar, şiirler, } \\
\text { polisler }\end{array}$ \\
\hline
\end{tabular}

Tablo 2 İsimlerin iki temel semantik sınıf içerisinde dağılımı 
Bu iki farklı anlam düzeyine ait isimlerin şiirindeki karışımının [bir araya getiriliş şekli], doğa ile insan arasında bir bağlantı olarak algıladığımız şeyi açıkladığ1 söylenebilir. Şiirle ilgili ilk izlenimim, bu iki unsur arasında bir tür çatışma olduğudur ve bu kısmen yukarıdaki tablo ile açıklanmıştır. İki soyut isim, rüyalar ve mucize, her iki kategoriye de ait olabilir ve bu iki anlam düzeyini birbirine bağladığı görülebilir.

Şimdi şiirdeki fiillere bakarsak, bu filleri okuduğumuzda bir yakınlık (immediacy) duygusu yarattığını görebiliriz. Ayrıca karşıdaki kişiye hitap edildiğini anlamamıza katkıda bulunur. Zamanla işaretlenen bütün fiiller (sonlu fiiller) şimdiki zamandadır. Geniş zamandaki eylemler 'barks' (havlar) [2], olmak filli 'is' [19] 'arrives'(ulaşır) [24] ve devamlılık gösteren şimdiki zaman kipinde yazılan 'are [eagerly] tumb/ling' (istekle y1kılıyor) [6/7/8] ve 'o-p-e-n-i-n-g/are' (açıl1yorlar) [12/13] şeklinde şiirde kurulur. Yakınlık duygusunu oluşturmaya yardımcı olmanın yanı sıra, ilerici mevcut katılımcılar "yıkılıyor" ve "açılıyor", eylemlerin devam eden "gergin” doğasını gösterir. Bu, doğanın kaçınılmazlığı fikrine katkıda bulunur- Şair konuştuğunda bahar da gelir. Bu aynı zamanda hız (quickly), heyecan (delice, hevesle) ve kaçınılmazlık (geri dönülemez) gibi anlamlar ifade eden dört zarf biçimiyle de desteklenir.

Şiirin başka bir kişiye hitap etmesinin hissettirilmesi, fiillerin emir kipiyle kullanılması sonucu elde edilir. Şiirdeki fiillerin 12 tanesi (dinle, bak, gel (x2), koş (x2), zıpla, bağır, gül, dans et, ağla, söyle) bu kiple kullanılmıştır. Emirler idare etmek ve yönlendirmek etmek için kullanılabilir; (makaleni hazırla!), davet etme (içeri girme), uyarı (kafanıza dikkat edin) vb. 'Dinle' şiirinde emirler, (1)'in yerine getirilmesi ve muhatabın, bahar konuşmacısının kutlamalarına katılmaları için çağrıda bulunurlar ve (2) mutluluk duygularını paylaşmak ve katkıda bulunmak için kullanılırlar (örneğin, mısralarda 'run run/with me now' ve 'sing for it's Spring'). Not: Son kıtada ikinci şahıs zamiri 'sen/you', 29 numaralı mısrada bu muhatabına 'sevgilim' diye hitap etmesi konuşmacı ile konuştuğu kişi arasında romantik bir ilişki olduğunu gösterir. ${ }^{2}$

2 Metinsel bir kanıt olmadığı için konuşmacının erkek olduğu sonucuna varamayız. Bununla birlikte, "sevgilim” muhtemelen bir erkek tarafından bir kadına söylediği için şematik varsayımlarımız konuşmacıyı bir erkek olarak hayal etmemizi sağlar (tabi ki, bu sadece bir varsayımdır; bu hipotezi, konuşma İngilizcesinin bir cümlesinde "sevgilim" kelimesini uyumlu hale getirerek test edebiliriz). Ayrıca, okuyucunun bir şiirdeki kişi ve şairin aynı olduğunu varsayma eğilimi vardır. Çünkü şiir yazarının erkek olduğunu biliyoruz, bu yüzden de kişinin erkek olduğunu varsayıyoruz. 
Şiirde alış1lmadık bir söz-mesela yeni kelime (neologism)-ve Cummings' in sıklıkla diğer şiirlerinde kullandığı alışılmadık bir bağdaştırma yok. Ancak, bazı kelimeler sayfada garip bir şekilde düzenlenmiştir. Misal, harika (wonderful) kelimesi iki satır boyunca geçer ve sonuç olarak çok ön plandadır. Kelimeyi biçimbirimlere bölmek, (wonder ve ful) bize iki yorumlayıcı etki sağlar. Önce kelimeyi isim olarak (wonder) ve sonra sıfat şeklinde (wonderful) okuruz. Buradaki yazıbilimsel (graphological) sapma kelimeyi ön plana çıkarır ve anlam yoğunluğu yaratır. Sapma, 'Dinle'de böyle belirgin bir özellik olduğundan, daha ayrıntılı olarak incelenmeye değer. Paralellik ve bunun yarattığı önleyici etkileri de değerlendirebiliriz.

\subsection{Sapma ve Paralellik}

Belki de listen 'Dinle'deki sapmanın en çarpıcı yönü, normalde büyük olmasını bekleyeceğimiz harflerin neredeyse sürekli küçük kullanımıdır. $\mathrm{Bu}$, Cummings'in şiirinin tipik bir örneğidir ve bu yüzden ona, sıradan, gelenekten kopma arzusundan başka, büyük bir önem atfetmeyiz. Ancak, bu yazıbilimsel (graphological) sapmanın etkilerinden biri, Cummings'in büyük harf kullandığ herhangi bir örneği ön plana çıkarmaktadır.

Şiirde ilk kez büyük harfle 19'uncu satırındaki "Bahar" kelimesiyle karşılaştığımızdan bu kelimenin önemli bir kavram olduğunu söyleyebiliriz. Aynı şekilde, şiirin [31] son mısra1, büyük harfle başlayan her kelimeyle büyük ölçüde ön plana çıkarılmıştır. Bu, burada ifade edilen düşünceyi vurgular; yani hiçbir şey (en azından tüm şiir) ve kimse, polisler gibi geleneksel olarak güçlü insanlar bile, Bahar'ın ilerleyişini ya da şairin muhatabına olan sevgisini durduramaz. Cummings belki de "polisleri” insanların güçlü bir prototip örneği olduğu için seçiyor.

Yazıbilimsel (graphological) sapmalara ek olarak, şiirde birtakım dilbilgisel sapmalar da vardır. Bunların çoğu, Cummings' in normalde gerekli olmayacağ 1 noktalama işaretlerini kullanma eğiliminden kaynaklanır. Böylece, örneğin, aynı anda gerçekleşen iki olayın nosyonunu ifade etmek için gramatiksel bir ihtiyaç yoksa tabirler parantez içine alınır. 12. ve 13. mısralardaki - 'o-p-e-n-i-n-g/are (leaves; flowers) dreams' buna örnektir. Burada, 13. mısraının köşeli kısmı, şairin rüyalarının metaforik olarak açılmasıyla eş zamanlı olarak yaprak ve çiçeklerin 
fiziksel olarak açıldığı anlamına gelir. Yine bu, şiiri çok aktif ve dinamik olarak anlamamıza katkıda bulunuyor. Burada ek anlamsal sapma dikkate alınmalıdır, yani rüyalar gerçekte açık olamaz ve dolayısıyla mısraın bu parçası da ön plana çıkmaktadır. Muhtemelen baharın gelmesiyle konuşmacının rüyalarının ve solumasının daha fazla farkında olduğunu, alıcı ve korumasızlık anlamında daha fazla 'açık'/ 'open' olduğunu önermektedir.

Cummings, dilbilgisi kurallarını bozarak aynı anda meydana gelen çok sayıda düşüncenin fikrini yakalamaya çalışır. Paranteze alınmış ifadeler kullanılmasına ek olarak, ad grupları genellikle noktalama olmadan birliktedir (ör. Misra 3 ile 6 ve misra 22) ve biz aynı cümlede hem kesin hem de belirsiz referans buluyoruz ('bir köpek havlaması'; bunun olası bir açılaması, konuşmacının belirli bir köpeğe başvurduğunu göstermek için kullanılır, ama aynı zamanda, konuşmacı hayvana aşina olmadığı için de [köpek havlamasını- a dog barks] kullanılır, yani köpeğin ismini bilmez. Kesin ve belirsiz bir referans kullanarak şair bu fikri taş1yabilir.). Bu özellikler, hatırlarsak, Blackmur’un (1954) ‘özellik’ olarak reddettiği şeydir. Ancak, bunları yakından incelersek, sapmaların sistematik olduğunu ve anlamlara gerçekten katkıda bulunduğunu görebiliriz. 7. ve 8. mısralarda bunun bir örneğini görebiliriz. Burada, Cummings, tumbling (yık1lma) kelimesini ilerleyen biçembirimi (morpheme) (-ing) ayrı bir mısrada görünmesi için böler. Bu, fiili ön plana çıkarır ve aynı zamanda homolojik bir etki ya da Short'un (2000) tanımladığı gibi 'grafoloji sembolik' etki yaratır. Bu bir kelime veya bir metin parçasında, gerçekte temsil ettiği kavram gibi görünüyor- örneğin, eğer kelimeyi 'outline' ya da ' $w^{\circ} b^{b} l_{y}$ ' şeklinde yazsaydım. 7. ve 8. mısralarda, fiil, bir satırdan diğerine "kopar" "tumble" gibi görünür ve bu nedenle eylemin şiir içinde önemli bir kavram olduğunu anlarız. Benzer şekilde, 12. mısrada Cummings, ilerici katılımcılığı sağlamak amacıyla "opening”’in, bileşen harflerini ('o-p-e-n-i-n-g') alışılmışın dışında noktalama işaretleri kullanarak böler. Yine bu, fiili ön plana çıkarır ve fiilen 'opening' kelimesinin homolojik (homological) etkisini yaratır. Ayrıca, kısa çizgiler de, açıklığın uzun, çizilmiş bir süreç olduğunu, bilhassa çiçeklerin ortaya çıktığı yavaşlığı andırdığını, özellikle de sözcükler ve noktalama işaretleri arasında boşluk olmayan takip eden mısra ile zıtlaştığını gösterir. 
Şiirde yazıbilimsel (graphological) sapma olaylarına yakından bakarsak, dinamik fillleri ön plana çıkarmanın genellikle işe yaradığını görebiliriz - bunlar bir tür eylemi ima eden fiillerdir. 10 mısradaki 'look' (bak) buna bir örnektir. Mısra tek bir fiilden oluşur, zorunlu ruh hali her iki tarafında da bir tire (-) ile ön plana ç1karılmıştır. 14. mısraın başlangıç fiili de alışılmışın dışında (mısraa başlamak için virgül kullanılır) noktalama işaretiyle öne çıkarılır. Ve 11. mısrada 'selves, stir: writhe' fiiller (colon) iki nokta üst üste imi (:) ile bağlanır ve kelimelerin arasında boşlukların olmamasıyla dikkat çeker.

Diğer eylemler farklı şekillerde ön plana çıkar. 15. mısrada tekrara düşen kelimeler vardır, 16., 17. ve 18. misralarda fiiller parantez ile yeni bir misrada, noktasız listelenmiş olarak görünür. Ve 12. mısra bir dizi farklı düzeyde ön plana alınmıştı;; yazıbilim (graphology) (daha önce belirttiğimiz), gramer (Bu, cümlenin vurgusunu eyleme geçirme etkisine sahip olan özne-fiil-nesne olarak beklenen kelime düzeninin tersine çevrilmesiyle) ve anlamsal - dinamik bir fiilin öznesi olarak işlev gören cansız bir soyut isimi "rüyalar” fonksiyonlandırır. Bütün bu sapmalar dikkatimizi 'Dinle'deki eylemlere odaklıyor ve şiirin sahip olduğu hissi son derece dinamik hale getiriyor. Öyleyse, bizim üslup analizimizin, şiirin yorumlanmasında ilk baştaki emsalimizi koruduğunu görebilirsiniz.

Şiirdeki biçimsel sapmaya ek olarak, şiirin dörtlüklerle düzenlenmesi konusunda bir dereceye kadar yazıbilimsel (graphological) paralellik mevcuttur. Şiirin yazıbilimsel (graphological) kuruluşunu tanımlamanın birkaç yolu vardır. Şiir, belki altı mısradan ve şiirin sonunda ayrı bir mısradan oluşan beş kıta olarak görülebilir (her bir kıtanın ilk mısraı diğer beş mısradan bir satır boşluk ile ayrılmıştır). Alternatif olarak, beş mısradan oluşan beş kıta ve bunların arasına serpiştirilmiş tekli mısralar olarak da tanımlayabiliriz. Nasıl görmeyi tercih ederseniz, şiir kendisini o düzende gösterir. Bunun ilk görünmesi bir kaotik grafolojik (graphological) kargaşa değildir. Ne olduğunu bilmek zor olsa da şiirin paralel yapısını oluşturmak ve onu şiirle ilgili ilk izlenimimizle ilişkilendirmek istiyorsak, bu oldukça hoş bir yorum olacaktır. Bununla birlikte, bir dizi Cummings şiirini inceleyen bir araştırmacı, şiirinde grafolojik (graphological) paralelliklerin önemli bir üslup özelliği olduğunu ileri sürmektedir. Dixit (1977) E. E. Cummings'in şiirlerini ayrıntılı olarak incelemiş ve sonuç olarak sapmaların keyfi örnekler ol- 
maktan uzak, aslında şiirlerin, sistematik sapmalar olduğunu ifade eder. Bunu şöyle açıklar:

Şair bahar hakkında konuşmayı seçtiğinde, şiiri, mevsimler gibi, düzenli bir döngüsel yapı sergiler.

Açıkçası, Cummings'in şiirde yaptığı gibi yapılandırması hiç de kazara değildir ve yukarıdaki neden, olası bir açıklamadır.

Şiirdeki bir başka paralellik, belirli seslerin tekrarını bulduğumuz fonolojik düzeyde gerçekleşir. 'Dinle'de düzenli herhangi bir kafiye şeması olmamasına rağmen (aslında sayfadaki yazıbilimsel (graphological) organizasyonunun düzenliliği serbest şiir olmaktan kurtarır), Cummings, şiirdeki belirli noktalarda iç kafiye kullanır. Şiirin oluşumu için katı bir model yoktur, ancak son iki hariç her kıtada bir miktar fonolojik (phonological) paralellik vardır. ${ }^{3}$ Sıklıkla aşağıdaki örneklerde görebildiğimiz gibi, birbirine yakın olarak sesli harflerin tekrarını buluruz (tekrarlanan sesli harfler kalın (bold) gösterilmektedir):

how crazily houses

/hau kreızılı hauzəz/

eyes people smiles

/arz pi:pal smarlz/

steeples are eagerly

/sti:pəlzəri:z1l1/

...wonder/ful sunlight

/wondəfəl sonlatt/

,come quickly come

/kom kwıklı kom/

sing) for it's Spring

/sın fərı?s prıy/
[3] nasıl da çılgınca evler

[4] gözler insanlar gülüşler

[6] kuleler istekle

[8,9] mükemmel günışı̆̆1

[14] gel çabucak gel

[19] Bahar olduğu için şarkı söyle

\footnotetext{
3 Sondan bir önceki bölümdeki fonolojik paralelizm yokluğu belki de şiirdeki bu aşamada son dörtlüğe ulaştığımızda dilin "normal" hale gelmesiyle açıklanabilir. 24. mısradaki sapmış noktalama işareti ve 25. mısradaki parantez kullanımından dolayı şiirin sondan bir önceki dörtlüğ̈̈ hâlâ biçimsel olarak tuhaftır.
} 
Bundan anlayabileceğimiz şey, son dörtlükteki fonolojik paralelliklerin yokluğunun, yine şiirin bu kısmını ön plana çıkarmasıdır. Son dörtlük, yorumlama açısından önemli olduğunu düşündüren sapma ile yoğundur.

\subsection{Son dörtlükte öne çıkan uyum}

Şimdiye dek gördüğümüz gibi, 'Dinle'nin son dörtlüğünde güçlü bir ön plana çıkarma vardır. Leech (1969) bunu, bir kerede çok farklı ön plan türlerinin ortaya çıktığı yer olan ön plana çıkarmanın 'uyumu' olarak tanımlar. Bu, şiirin yorumlanması için çok önemlidir, ancak anlamla ilgili genel bir sonuca varmadan önce, burada neyin tam olarak ön plana konulduğunu bir kez daha düşünelim.

Öncelikle, her satırın son satırdaki ilk büyük harfle fark ettiğimiz iç sapma vardır. İkincisi, diğer bölümlerden farklı olarak, herhangi bir fonolojik paralellikten yoksundur ve (belirgin noktalama işaretlerini göz ardı ederek), bölümün dilbilgisel düzeni, sözdiziminin geleneksel kurallarını izler. Bu ön plana çıkan unsurlar hakkında ilginç olan şey, bunların hepsi içsel sapmanın bir sonucudur ve hepsi yazı dilimizin normal beklentilerine uyarlar! Şiirin diğer bölümlerdeki çok sayıdaki sapma özelliklerine ek olarak, son dörtlükte sahip olduğumuz şey bir tür “ters” sapmadır. 'Dinle'nin en güçlü ön plana çıktığı özellikler, genellikle 'normal' olarak tanımlayabileceğimiz özelliklerdir.

Tüm bunların etkisi son dörtlüğü anlayabilmemiz için onu olağandışı kolay hale getirir. Eseri yorumlamak zor değildir (şiirin geri kalanına kıyasla) ve böylece şiirin son mesajı son derece net hale getirilir; hiçbir şey ve kimse Baharın ve şairin sevgisinin ilerlemesini durduramaz - belki de, bu güçlere karşı mücadele etmememiz gerekir, kendimizi sadece dışarıdan) kabul etmeliyiz.

\section{Sonuç}

Şimdi şiiri biçimsel olarak inceledik, çalışmamıza sonuç yazabilecek konumdayız. Burada ilk yorumunuzun açık olup olmadığına ve belki de sizin hesaplayamadığınız metnin özelliklerine bakabilirsiniz.

'Dinle'nin analizi, bir şiirin yorumlanmasını desteklemek için üslupları nas1l kullanabileceğimizi ve bir şiirin vurgulanmış unsurlarını nasıl gözden kaçırabileceğimizi gösteriyor. Bu aynı zamanda, E. E. Cummings'in ‘Dinle'de böylesine 
garip stilistik teknikleri kullanmayı tercih etmesinin nedenini daha kesin bir şekilde belirleyebilmemizi sağlar. Örneğin, sapkın noktalama işaretinin hareketli fiillerin ön plana çıkarılmasıyla ilişkilendirildiğini gördük. $\mathrm{Bu}$, şiirde neden bu kadar çok "hareketi" algıladığımızı açıklayan bir unsurdur. Şiirin stilistik olarak ele alınması, hem gündelik iletişimde hem de şiir içinde "normal", sapkın olmayan bir dil olduğunu düşündüğümüz şiirin en içsel olarak sapkın özelliklerinin nasıl ve neden olabileceğine dair bir sebep öne sürdüğünü vurgular. Stilistik, o zaman, başka türlü anlamadığımız bir metnin bölümlerini açıklamada yardımcı olur.

Şiirin açıklayamadığım belli özellikleri var. Örneğin, 11. mısrada "selves" ve "stir" arasındaki virgülü açıklayamıyorum ve 23. satırdaki "every" ifadesinin hemen öncesinde yer alabileceğinden emin değilim. Bu faktörleri açıklayabilen stilistik bir çözümleme (stylistic analysis) söylediğim şeyleri hükümsüz kılabilir.

Genel olarak, bir şiirin dilsel özelliklerinin doğrudan anlamla nasıl ilişkili olduğunu gösterdim ve bunu yaparken 'Dinle'deki ilk yorumumu destekledim. Elbette, şiire verilebilecek tek yorum benimki değildir. Ancak, stilistik gibi sistematik bir analitik teknik kullanarak, yorumumuzun gerçekte olduğu gibi açık ve ayakları yere basan olmasını sağlayabiliriz. Ayrıca, şiirin başka herhangi bir üslup çözümlemesinin benim çıkarımlarımdan en azından bir kısmını içerme olasılığı yüksektir. Bir metnin niçin belirli bir şekilde hissettirdiğini nasıl açıklayacağınızı ve üslupların edebî metinleri yorumlayan herkes için kullanışlı bir araç olduğunu size inandırmak için bir yol kat ettiğimi umuyorum. 


\section{Kaynakça}

Blackmur, R. P. (1954) Language as Gesture: Essays in Poetry. London: George Allen \& Unwin Ltd.

Cummings, E. E. (1964) 73 Poems. London: Faber and Faber.

Dixit, R. (1977) 'Patterns of Deviation in Selected Poems of E. E. Cummings.' Unpublished M.A. dissertation. Lancaster University.

Fowler, R. (1971) The Languages of Literature. London: Routledge \& Kegan Paul.

Leech, G. N. (1969) A Linguistic Guide to English Poetry. London: Longman.

Short, M. (2000) 'Graphological Deviation, Style Variation and Point of View in Marabou Stork Nightmares by Irvine Welsh.' Journal of Literary Studies/ Tydskrif vir Literatuur Wetenskap 15 (3/4): 305 - 323.

Van Peer, W. (1980) 'The Stylistic Theory of Foregrounding: A Theoretical and Empirical Investigation.' Unpublished Ph.D. thesis. Lancaster University.

Van Peer, W. (1986) Stylistics and Psychology: Investigations of Foregrounding. Croom Helm. 